Em seu livro Financial markets, money and the real world, Paul Davidson (2002, p.114) sustenta que:

"Animal spirits depend in large part on the criative imagination of the entrepreneurial class. Obtaining the claims on resources necessary to put creative ideas into capital facilities requires the positive cooperation of the central bank, the banking system and the nonbank financial community. [...] The presence of the properly designed accommodating (endogenous money) banking system and associated financial intermediary institutions provide the potencial to contribute significantly to a golden age of economic development and growth."

No caso brasileiro, a existência de títulos públicos indexados à taxa Selic, subproduto de uma estabilização monetária operada sem a supressão do "dinheiro financeiro", representado pela indexação dos papéis do governo aos juros básicos, torna o setor bancário ainda mais disfuncional ao desenvolvimento econômico e social. Com efeito, os bancos no Brasil acabam contribuindo para o "gray age" da economia brasileira, pois de modo geral não permitem a transformação das idéias criativas dos empresários em planos efetivos de investimento capazes de dinamizar o ciclo de negócios. A anomalia gerada pela existência de um ativo com características peculiares não permite a cooperação sugerida por Paul Davidson entre a autoridade monetária, o sistema bancário e a comunidade financeira não-bancária em prol do desenvolvimento.

O livro organizado por Luiz Fernando de Paula e José Luís Oreiro constitui, assim, um importante marco para o entendimento do setor bancário brasileiro contemporâneo, pois lança luz de forma séria e competente aos principais motivos que impedem a construção de um sistema financeiro plenamente eficiente. Trata-se, por isso, de leitura obrigatória para todos aqueles que buscam compreender o sistema financeiro nacional.

Giuliano Contento de Oliveira Doutorando em Economia no IE/Unicamp

\title{
Emprego, Juros e Câmbio: finanças globais e desemprego
}

\section{João Sicsú}

Rio de Janeiro: Elsevier, 2007.

A principal obra de John Maynard Keynes, A Teoria Geral do Emprego, do Juro, e da Moe$d a$, nasceu como reação ao pensamento econômico dominante à época de Keynes, e que nas últimas décadas voltou a ser hegemônico após a nova roupagem que lhe foi dada pela "revolução monetarista”. Keynes propôs um novo paradigma para a ciência econômica. Neste, os conceitos de tempo, de incerteza e de moeda são cruciais para se entender a dinâmica da economia capitalista e implicam a inadequação da teoria (neo)clássica.

O livro Emprego, Juros e Câmbio: finanças globais e desemprego de João Sicsú, professor da Universidade Federal do Rio de Janeiro, possui vários méritos. Entre estes está o contraponto, feito de modo recorrente, entre o pensamento econômico dominante e a visão alternativa proposta por Keynes e pós-Keynesianos. Assim, Sicsú contribui para desmistificar a idéia do pensamento único em economia ao apontar caminhos alterna- tivos que podem ser seguidos com êxito pela política econômica. Outro ponto forte do livro está na dupla abordagem feita pelo autor: este trabalha, de modo equilibrado, aspectos teóricos e empíricos da macroeconomia. Esta dupla abordagem facilita tanto a compreensão da teoria pós-Keynesiana como também a interpretação da realidade das economias contemporâneas. Isto nos leva a outro mérito do livro, que está no tratamento de questões atuais e relevantes referentes à política macroeconômica no Brasil e no mundo.

O livro tem como tema central a análise do funcionamento das economias modernas e das políticas requeridas para se alcançar o crescimento econômico sustentado e a redução do desemprego num contexto de estabilidade de preços e de equilíbrio do setor externo da economia. O livro está dividido em seis partes. Na parte I, Sicsú aponta equívocos e inconsistências no pensamento da Escola novo-Keynesiana à luz da economia 
de Keynes, e apresenta algumas lições derivadas Escola pós-keynesiana.

A parte II do livro tem como tema central a política monetária. O autor desenvolve o argumento de neutralidade da moeda com base na Escola Novo-Clássica, para, em seguida, apresentar críticas a este argumento e, com a perspicácia que lhe é peculiar ao longo de todo o livro, demonstrar a inconsistência do argumento de Kydland e Prescott de neutralidade da moeda no curto prazo. Ainda, com base no conceito de "normalidade econômica", o autor demonstra que a política monetária pode ter êxito em estimular o crescimento e o emprego, a despeito da presença de defasagem temporal externa na condução de tal política - a defasagem interna seria um equívoco. Isto posto, Sicsú elabora o argumento pósKeynesiano de não neutralidade da moeda e discute os critérios relacionados ao uso eficiente da política monetária discricionária, os instrumentos e mecanismos de operação dessa política, e sua capacidade de estimular o crescimento econômico e o emprego. $\mathrm{O}$ autor ainda analisa as causas da inflação e a inadequação do seu combate por meio da política monetária, mesmo sendo esta eficaz para tal propósito. Nesta parte reafirma-se o reconhecimento de Keynes e pós-Keynesianos dos males causados pela inflação e a necessidade premente de combatê-la, e apresentam-se as políticas antiinflacionárias propostas pelos póskeynesianos.

A parte III do livro possui como co-autor o professor Fernando J. Cardim de Carvalho, e trata do debate teórico e empírico acerca dos controles de capitais. São apresentados argumentos favoráveis e contrários à liberalização financeira. Conclui-se que os controles de capitais são importantes para isolar a economia de choques externos e proporcionar autonomia para a política econômica doméstica. Os autores ainda demonstram que taxas de câmbio flutuantes não substituem os controles de capitais no seu papel de estabilizador da economia, e, em seguida, mostram os resultados empíricos inconclusivos nesse campo. Por fim, analisam o caso da Malásia, que adotou controles sobre a entrada de capitais em 1994 e sobre a saída em 1998. Em ambas as situações a política de controle de capitais operou com êxito, contrariando as previsões pessimistas e reações adversas, então adotadas pela comunidade financeira internacional (de cunho liberalizante).

Na parte IV do livro faz-se, com sucesso, um estudo da liberalização financeira aplicado ao caso brasileiro. Sicsú trata das conseqüências das normas cambiais adotadas pelo Banco Central do Brasil em 2005, que consolidam e aprofundam o atual estágio de liberalização financeira no país. Em especial, o autor avalia que a flexibilização (ou mesmo o fim) da cobertura cambial nas exportações favorece um quadro de elevadas taxas de juros domésticas, com efeitos deletérios sobre as contas do governo e sobre o crescimento econômico. Em seguida, descreve-se o processo de liberalização financeira brasileira com base nas normas cambiais, iniciado em 1988. Ainda, demonstra-se que a liberalização financeira expôs a economia brasileira a riscos elevados, abrindo os canais legais que conformaram as seis crises cambiais vividas no Brasil entre 1995 e 2002.

A parte $\mathrm{V}$ do livro trata da teoria e das evidências do regime de metas de inflação. Por meio de interessante trabalho empírico, Sicsú demonstra que a inflação caiu nos últimos anos tanto no grupo de países que adotaram o citado regime como também nos países que não o adotaram. Ademais, as evidencias empíricas sugerem que o regime de metas de inflação não estimula o crescimento econômico. Em seguida, o autor demonstra o que a proposta de autonomia do Banco Central do Brasil (BCB) esconde. Visto que autonomia para a tomada de decisão sobre questões técnicas deve ser prerrogativa de qualquer órgão público, a proposta de autonomia para o BCB estaria sendo usada para desviar a atenção do público de tema mais relevante: quais devem ser os objetivos e o papel do BCB? Ele deve mirar apenas uma meta de inflação ou deve perseguir também o crescimento econômico e o emprego?

Ainda, a citada proposta esconde a hipótese de que a taxa de juros é o único instrumento eficaz de combate à inflação. $\mathrm{O}$ autor desmistifica a idéia de que só a política de juros (nociva ao crescimento do emprego e da renda) pode controlar a inflação, e apresenta políticas antiinflacionárias alternativas. Por fim, Sicsú demonstra a fragilidade da hipótese de viés inflacionário (inflationary bias) dos governantes, e faz uma crítica à tese de independência do Banco Central, sugerindo que tal independência pode implicar conflitos entre as políticas monetária e fiscal e políticas econômicas ineficientes.

$\mathrm{Na}$ última parte do livro é feita uma avaliação do governo Lula entre 2003 e 2006 nos campos da economia e da política. Demonstra-se a estratégia do capital financeiro de blindagem de seus interesses e a conversão do PT ao credo conservador-liberal, que é definitiva e representa uma 
derrota estratégica para toda a esquerda brasileira. Segundo o autor, uma crise nos mercados financeiro e cambial do país não eclodiu à época da crise política de 2005 porque a insegurança só surgiria nos mercados se a crise se aproximasse do Palácio do Planalto, “já que o presidente Lula era a âncora legitimadora do modelo. Ele era o elo entre a política e a economia”.

Argumenta-se que não há blindagem da economia visto que sua vulnerabilidade externa está mantida devido à liberdade para os fluxos de capitais especulativos. Assim, as recorrentes crises cambiais observadas no governo anterior só não se repetiram em função do cenário externo extremamente favorável que marcou todo o primeiro mandato do governo Lula da Silva. Em seguida, o autor demonstra que "entre a ruptura total (com o modelo econômico anterior) e a pura continuidade com aprofundamento, havia muito espaço e inúmeras possibilidades".

Por fim, Sicsú fecha o livro sob o tema Sistema Tributário e Controle de Capitais. Argumenta-se que a livre concorrência não promove uma distribuição de renda e de riqueza aceitável, como também não é capaz de alcançar ou de manter o pleno emprego. Assim, regras permanentes de Estado e políticas governamentais devem dirigir a economia para esses fins. Entre essas políticas está o estabelecimento de um sistema tribu- tário progressivo sobre os rendimentos e a rique$\mathrm{za}$, a universalização do acesso aos serviços e bens básicos (saúde, educação, moradia, terra, cultura, lazer) e os controles de capitais.

Trata-se, portanto, de livro relevante para aqueles preocupados com o crescimento da economia e do emprego e com temas atuais e centrais da economia mundial e do Brasil, tais como políticas antiinflacionárias, controles de capitais e independência do Banco Central. Esta obra de João Sicsú vem em boa hora, dadas as baixas taxas de crescimento da economia brasileira e a insatisfação de diversos setores da sociedade em relação ao continuísmo da política econômica no Brasil. Visto que estimula a pensar e aponta alternativas de política econômica à atual, capaz de alcançar não apenas a estabilidade de preços, mas, também, o crescimento sustentado da economia e do emprego, o livro é muito útil e interessante para diversos grupos de pessoas: economistas, inclusive professores e alunos de graduação e de pós-graduação em economia, e pessoas de outras áreas de formação, inclusive jornalistas especializados e formuladores de políticas públicas.

Marco Flávio da Cunha Resende Professor do Departamento de Economia da Universidade Federal de Minas Gerais 